\title{
Manufacturing of Tubular Dead-End Membranes by Continuous Thermoplastic Extrusion
}

\author{
Mehdi Salehi \\ Laboratory for High Performance Ceramics, Empa, Swiss Federal Laboratories for Materials Science and Technology, \\ Ueberlandstrasse 129, Duebendorf CH-8600, Switzerland \\ The Fribourg Center for Nanomaterials (FriMat), Department of Geosciences, University of Fribourg, Pérolles Ch. du Musée 6, \\ Fribourg CH-1700, Switzerland
}

\section{Ewald M. Pfaff and Anke Kaletsch}

Institute for Materials Applications in Mechanical Engineering, RWTH Aachen University, Nizzaallee 32, Aachen 52072, Germany

\section{Thomas Graule and Frank Clemens* \\ Laboratory for High Performance Ceramics, Empa, Swiss Federal Laboratories for Materials Science and Technology, Ueberlandstrasse 129, Duebendorf CH-8600, Switzerland}

\section{Bernard Grobéty}

The Fribourg Center for Nanomaterials (FriMat), Department of Geosciences, University of Fribourg, Pérolles Ch. du Musée 6, Fribourg CH-1700, Switzerland

Dense and gastight dead-end tubular $\mathrm{Ba}_{0.5} \mathrm{Sr}_{0.5} \mathrm{Co}_{0.8} \mathrm{Fe}_{0.2} \mathrm{O}_{3-\delta}$ (BSCF) membranes were fabricated by thermoplastic extrusion. Optimal feedstocks for the extrusion of dead-end tubular structures were obtained for a feedstock consisting of $89.83 \mathrm{wt} \%$ BSCF powder, $5.63 \mathrm{wt} \%$ ethylene vinyl acetate (EVA), $3.56 \mathrm{wt} \%$ paraffin wax (PW), and $0.98 \mathrm{wt} \%$ stearic acid (SA). Thermogravimetric analysis (TGA) was used to determine the thermal characteristics of the feedstock and to characterize the amount of binder removed during the wicking step. Straight and round dead-end tubular membranes with wall thickness of $0.5 \mathrm{~mm}$ could be achieved after sintering. The gastightness test showed that the membranes were leak-tight up to a pressure of 35 bar.

\section{Introduction}

Due to $100 \%$ oxygen permselectivity at elevated temperatures, dense ceramic membranes with high oxygen ionic and electronic conductivity have become increasingly competitive and are already under investigation as oxygen separation membranes, catalytic partial oxidation reactors, and cathodes in solid oxide fuel cells (SOFCs). ${ }^{1-4}$ BSCF has one of the highest oxygen permeability, and it has been investigated extensively for oxygen separation membranes. ${ }^{5,6}$

High-purity oxygen can be obtained using dense mixed ionic conductor ceramic membranes when there is a higher oxygen partial pressure on one side of the mem-

*Frank.clemens@empa.ch; chemehdi3333@gmail.com brane (feed side) than the other side (permeate side). The oxygen pressure gradient can be increased by compressing the air on feed side and/or by decreasing the oxygen partial pressure on the permeate side. The latter can be achieved using an inert sweep gas, for example, argon or helium, or by evacuating the permeate side. The use of a sweep gas requires a second separation process to separate the latter from the oxygen. In recent years, the use of sweep gas was abandoned, and the evacuation of the permeate side by vacuum pumps has become the method of choice to produce high-purity oxygen. Lowering the overall pressure on the permeate side enhances significantly the oxygen permeability. ${ }^{7-9}$ One of the major problems in using tubular membranes for the oxygen separation is sealing of the tube end. Because thermal expansion coefficients of most suitable sealing materials differs largely from the coefficients of 
the perovskite-based membrane materials, heating up of the membrane to operating temperatures may induce high thermal stresses, which may cause leakage across the joints interface. ${ }^{10}$ Therefore, shaping tubular membranes in form of the dead-end structures may obviate the sealing problems.

Fabricating dead-end tubular membrane is not a simple process, and different methods are used. Liang et al. ${ }^{7}$ have closed open BSCF tubes on one end by a thick disk of the same material before sintering, using a paste based on copper oxide to keep tube and plate together. The seal between tubes and plate was established during reaction-diffusion sintering in which the copper oxide functioned as sintering aid. $\mathrm{BaCo}_{\mathrm{x}} \mathrm{Fe}_{\mathrm{y}} \mathrm{Zr}_{1-\mathrm{x}-}$ ${ }_{y} \mathrm{O}_{3-\delta}$ (BCFZ) hollow fibers have been closed by gold plugs using Au paste. ${ }^{8}$ Wei et al. ${ }^{9}$ reported a novel method to produce the dead-end hollow fiber using a wet spinning/sintering method. After forming hollow fibers with two open ends by a phase inversion spinning process, one end of the fibers was coated with the same spinning solution followed by a second phase inversion process. However, they could solve the complexity and high cost of sealing a disk, but they still needed a twostep process to fabricate the dead-end hollow fiber membrane.

In this study, thermoplastic extrusion method was used to fabricate the dead-end $\mathrm{Ba}_{0.5} \mathrm{Sr}_{0.5} \mathrm{Co}_{0.8} \mathrm{Fe}_{0.2} \mathrm{O}_{3-\delta}$ (BSCF) tubular membranes in a single-step process.

Table I. Physical Properties of Binders Components Used in this Study

\begin{tabular}{llc}
\hline Binder Component & $\begin{array}{l}\text { Density } \\
\left(\mathbf{g} / \mathbf{c m}^{\mathbf{3}}\right)\end{array}$ & $\begin{array}{c}\text { Melting } \\
\text { point, } \boldsymbol{T}_{\mathbf{m}}\left({ }^{\circ} \mathbf{C}\right)\end{array}$ \\
\hline Stearic acid & 0.845 & 68 \\
Ethylene vinyl & 0.95 & 72 \\
acetate (EVA) & & \\
Polyethylene (PE) & 0.92 & 109 \\
Paraffin wax & 0.91 & 60 \\
\hline
\end{tabular}

\section{Experimental}

For the preparation of membranes, commercially available $\mathrm{Ba}_{0.5} \mathrm{Sr}_{0.5} \mathrm{Co}_{0.8} \mathrm{Fe}_{0.2} \mathrm{O}_{3-\delta}$ (BSCF) powder (Treibacher Industrie AG, Althofen, Austria), with a mean particle size of $3.8 \mu \mathrm{m}$ and a specific surface area of $1.55 \mathrm{~m}^{2} / \mathrm{g}$, was used. Ethylene vinyl acetate (EVA) (ELVAX250A, DuPont ${ }^{\mathrm{TM}}$; Geneva, Switzerland), polyethylene (PE) (1700MN18C Lacqtene PEBD, Arkema Group, Cedex, France), and paraffin wax (PW) (76231 Fluka AG, Buchs, Switzerland) were used as binders (Table I). Typically, a paraffin content for thermoplastic processing route is in the range between 40 and 60 vol.\%. In a previous study, a paraffin content of 40 vol.\% was used to achieve dimensionally stable thin tubular structures after extrusion process. ${ }^{11}$

Stearic acid (SA) was added as a surfactant (Fluka AG). The desired SA content was calculated based on the area occupied by one SA molecule and the specific surface area of the ceramic powder. According to practical results, this value has been tripled to achieve sufficient feedstock properties (e.g., low viscosity and homogeneity). ${ }^{12}$ Two different binder systems (Table II) were tested for the preparation of the thermoplastic feedstocks. Both formulations are based on a ceramic-polymer composite with $60 \%$ volume fraction of ceramic.

Prior to feedstock preparation, the BSCF powder was precoated with stearic acid. For the compounding, a high shear mixer (HAAKE PolyLab Mixer, Rheomix 600, Thermo Scientific, Karlsruhe, Germany) equipped with a pair of roller blades was used. The torque was recorded as a function of mixing time. The mixing process is described elsewhere. ${ }^{13}$

The rheology of the feedstocks was analyzed with a twin-bore capillary rheometer (RH7-2, Malvern, Herrenberg, Germany). The appeared viscosity was calculated from the total extrusion pressure and piston speeds. For the rheological investigations, a long capillary with a diameter of $1 \mathrm{~mm}$ and a length of $16 \mathrm{~mm}$ was used.

Tubular membranes were extruded through a 10-mm-diameter die and with wall thicknesses of 1 and

Table II. Formulations of the Two Different Feedstocks and Extrusion Conditions

\begin{tabular}{llll}
\hline Feedstock & Composition (wt $\%)$ & Extrusion Rate $(\mathbf{m m} / \mathbf{s})$ & $\begin{array}{c}\text { Extrusion } \\
\text { Temperature }\left({ }^{\circ} \mathbf{C}\right)\end{array}$ \\
\hline 1 & $89.83 \%$ BSCF powder, 5.63\% EVA, & $5-10$ & 68 \\
& $3.56 \%$ PW, 0.98\% SA & & 95 \\
2 & $89.83 \%$ BSCF powder, & 50 & \\
\hline
\end{tabular}


$0.5 \mathrm{~mm}$, using a capillary rheometer (RH7-2, Malvern, Germany). After the extrusion, one end of the tubes was closed manually with pliers, and the leakage can be simply investigated by a bubble point test. Solvent extraction and wicking followed by a thermal treatment were tested to remove the binder. The solvent extraction of paraffin was performed by immersing the green samples into an ethanol bath at $40-45^{\circ} \mathrm{C}$. The wicking step was carried out at $150^{\circ} \mathrm{C}$ and $4 \mathrm{~h}$ holding time to remove the paraffin. Thermal treatment was carried out at a heating rate of $10^{\circ} \mathrm{C} / \mathrm{h}$ up to $600^{\circ} \mathrm{C}$ in air. After binder removal, the tubular membranes were sintered at $1000^{\circ} \mathrm{C}$ for $2 \mathrm{~h}$ in air, using a heating rate of $60^{\circ} \mathrm{C} / \mathrm{h}$.

The tensile strength of sintered tubes $\left(d_{\text {outer }}=10 \mathrm{~mm} ; d_{\text {wall }}=0.9 \mathrm{~mm} ; L_{\text {tube }}=25 \mathrm{~mm}\right)$ was measured by a Zwick Z005 universal testing machine (Zwick GmbH, Ulm, Germany). The test settings were as follows: preload $0.5 \mathrm{~N}$, preload speed $0.5 \mathrm{~mm} / \mathrm{min}$, and test speed $1 \mathrm{~mm} / \mathrm{min}$. The tubes were applied lengthwise between two dies and loaded by compression forces. Leather clothes (very thin) were used as pressure pads to decrease frictional stresses and to avoid slippage of the membrane tube and the stainless steel plates during compressive strength testing. For calculation the failure tensile strength the following equation described elsewhere ${ }^{18}$ was used

$$
\sigma=\frac{P \cdot K_{4}}{\left(D_{0}-D_{i}\right) \cdot t}
$$

where $P$ is the load to failure, $D_{0}$ and $D_{\mathrm{i}}$ are the outside and inner diameter, $\mathrm{t}$ the width of the tubes, and $\mathrm{K}_{4}$ is an empirical determined stress constant, which is a function of the ratio $D_{\mathrm{i}} / D_{0}$ and the manufacturing method. For our extruded tubes $K_{4}$ was estimated as 7 .

The sintered membranes were tested for gastightness by feeding the tubes with pressurized air (2 bar, Fig. 1).

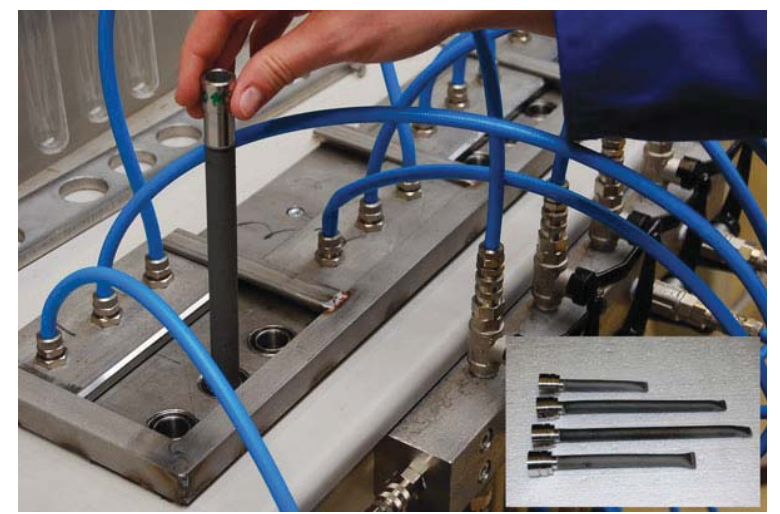

Fig. 1. Device for gas-tightness tests of the dead-end tubular membrane.

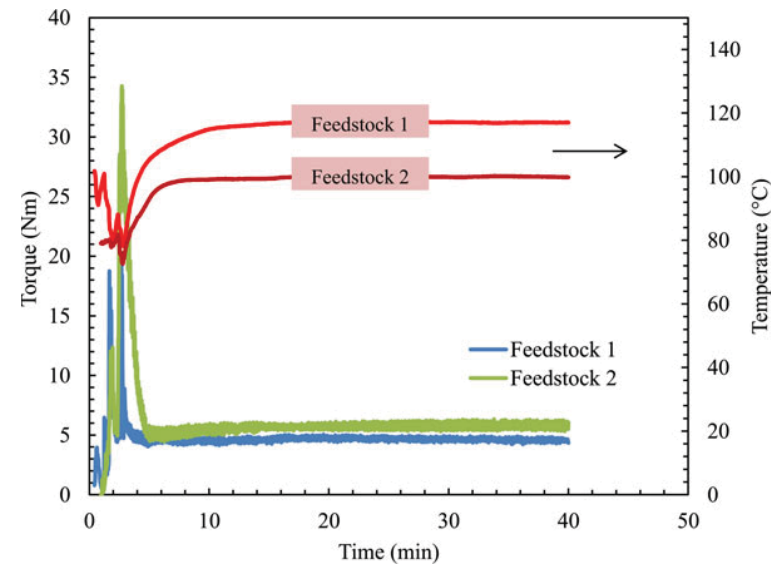

Fig. 2. Change of torque with mixing time for feedstock 1 and 2 .

The pressurized tube was submerged in water. Leaks could be detected by the appearance of bubbles. After testing the gastightness, the tubes were integrated in a burst test device to evaluate at which pressure the tubes fail, especially the dead-end part. In the test device, the tubes were pressurized with external air in steps of 2 bars at intervals of $1 \mathrm{~min}$ up to a maximal pressure of 35 bar.

\section{Results and Discussion}

Torque evolution for feedstock 1 and 2 is shown in Fig. 2. The binder components were first filled into the chamber. BSCF powder coated with stearic acid was then added and kneaded until the torque was stabilized. An increase in torque is associated with the initial addition of the powder. As soon as the particles are wetted by binder, torque decreases until reaching an equilibrium state.

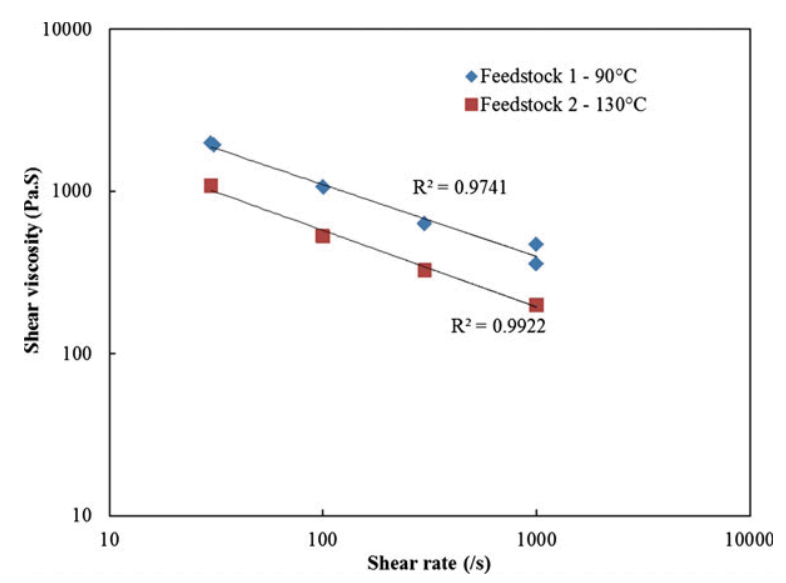

Fig. 3. Viscosity of feedstocks 1 (EVA+PW binder system) and feedstock 2 (PE $+P W$ binder system) as a function of shear rate. 
Figure 3 illustrates the rheological properties of feedstock 1 and 2 at different temperatures. Due to the difference in the melting point of PE and EVA (Table I), rheological measurements of the individual feedstocks were performed at different temperatures. It can be seen that the viscosity of the feedstocks decreases with increasing shear rate. This behavior is well known as the pseudoplastic or shear-thinning behavior.

Extrusion experiments, which have been carried out at the same temperatures used for the rheological measurements, led to strong deformation of the tubes during
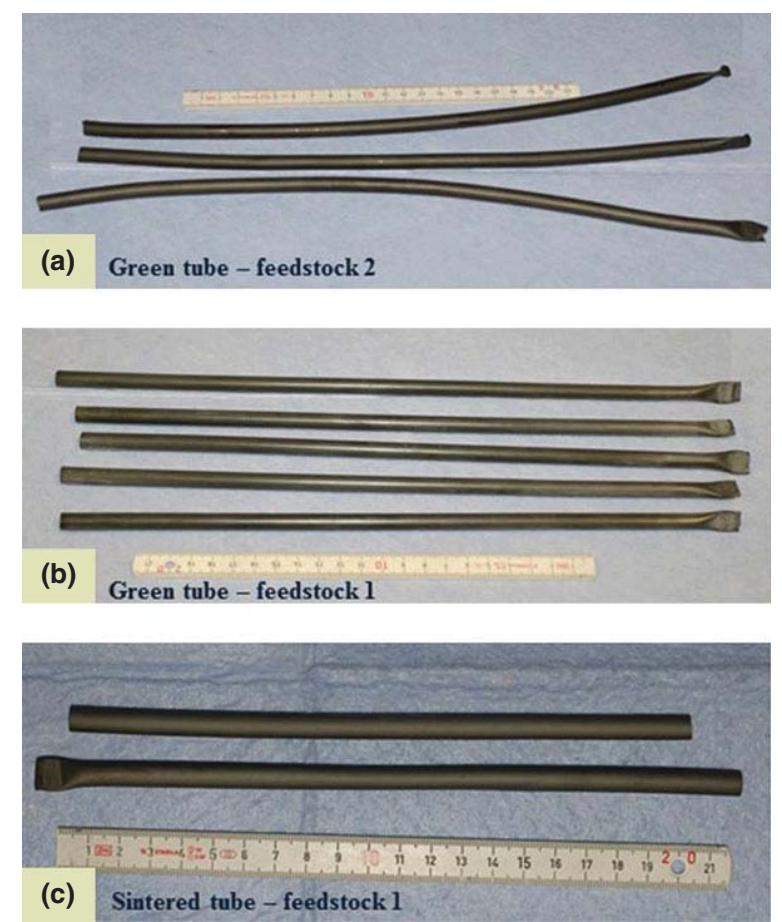

Fig. 4. Images of: (a) green tubes, feedstock 2 (b) green tubes, feedstock 1 (c) sintered tubes, feedstock 1 .

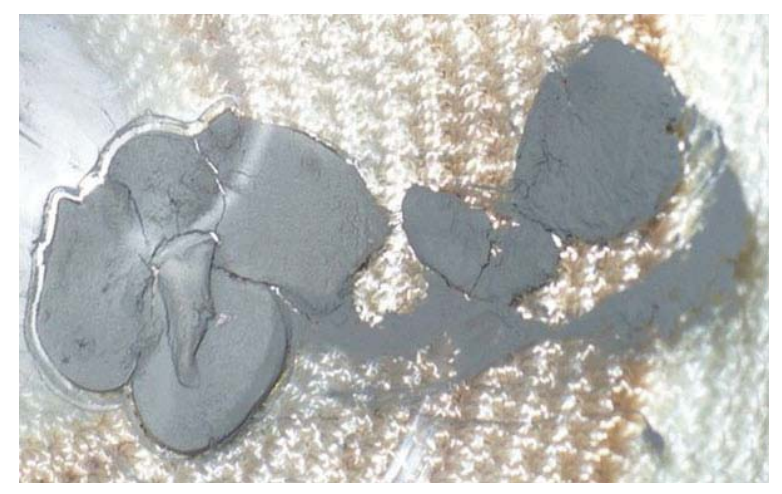

Fig. 5. Samples after solvent debinding in n-hexane. extrusion. Therefore, the extrusion temperatures were lowered for both binder systems (Table II). In this study, the best results were obtained for feedstock 1 (EVAbased system). For extrusion of feedstock 1, tubular membranes were extruded into ethanol $\left(\sim 30^{\circ} \mathrm{C}\right)$ below the nozzle to achieve quick solidification and therefore shape stability by quenching. The following debinding and sintering experiments were, therefore, only continued with samples prepared with feedstock 1 (see Fig. 4).

$N$-hexane or $n$-heptane is typically used for the removal of PW by solvent extraction. ${ }^{14,15}$ Preliminary tests with feedstock 1 revealed that the solubility of the binder system consisting of EVA, PW, and SA was too high in both solvents to use them for debinding (Fig. 5). This result is somewhat contradicting to others where $n$-hexane or $n$-heptane have successfully been used as solvent to remove a binder system consisting of EVA, PW, and SA. ${ }^{15,16}$

Instead ethanol was used at $40^{\circ} \mathrm{C} / 5 \mathrm{~h}$ for solvent extraction. When raising the temperature above $45^{\circ} \mathrm{C}$, slumps and cracks appeared in the membrane walls. After drying at room temperature, the samples showed deformation in axial direction (Fig. 6). This could be due to the contraction of leftover backbone polymer (EVA).

Owing to the negative results with solvent debinding method, wicking was therefore performed at $150^{\circ} \mathrm{C} / 5 \mathrm{~h}$

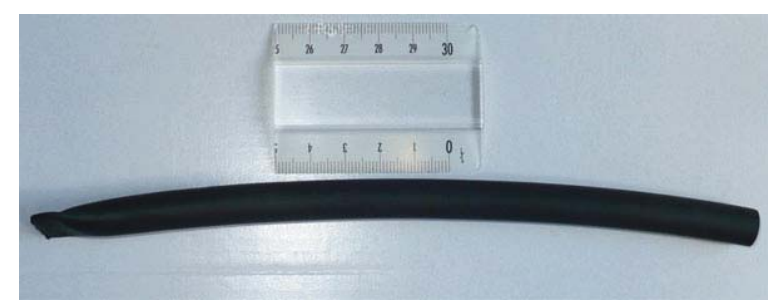

Fig. 6. Dead-end tube (feedstock 1) after solvent debinding in ethanol at $40^{\circ} \mathrm{C} / 5 \mathrm{~h}$ and drying at room temperature.

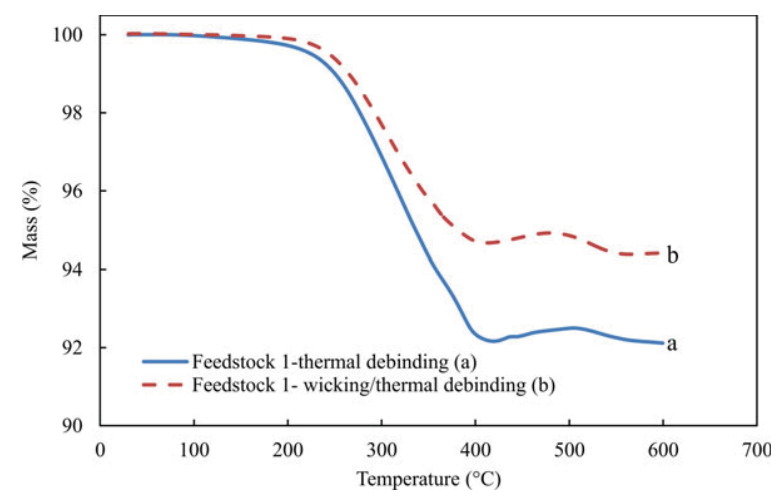

Fig. 7. Thermogravimetric analysis of feedstock 1: before and after wicking process. 
to remove SA and PW and subsequent thermal treatment up to $600^{\circ} \mathrm{C}$ to eliminate EVA and the leftover SA and PW. Figure $7 \mathrm{a}, \mathrm{b}$ shows the mass loss for both continuous thermal treatment and combined wicking/thermal annealing of feedstock 1 . When continuously heated up, the binder decomposition starts at $190^{\circ} \mathrm{C}$ and is completed at $550^{\circ} \mathrm{C}$ with a total weight loss of $8.54 \mathrm{wt} \%$.

The weight loss (Fig. 7b) in samples, which underwent a wicking debinding prior to the analysis, initiates at about $240^{\circ} \mathrm{C}$, around $50^{\circ} \mathrm{C}$ higher than the sample without wicking step. The difference between the two thermogravimetric analysis (TGA) curves shows (Fig. 7) that during the wicking debinding, about $70 \%$ of the SA and PW content in green sample is removed. This helps to create a pore network through which the gaseous breakdown products of the remaining binder components can diffuse to the surface of sample. There is an increase in mass with increasing temperature from $420^{\circ} \mathrm{C}$ to approximately $550^{\circ} \mathrm{C}$ due to carbonatization of BSCF. Infrared spectra taken from quenched samples contain two peaks characteristic for carbonate groups (Fig. 8).

The grain size distribution, grain orientation, and density of the sintered BSCF structures by thermoplastic processing have been published elsewhere. ${ }^{11,13}$

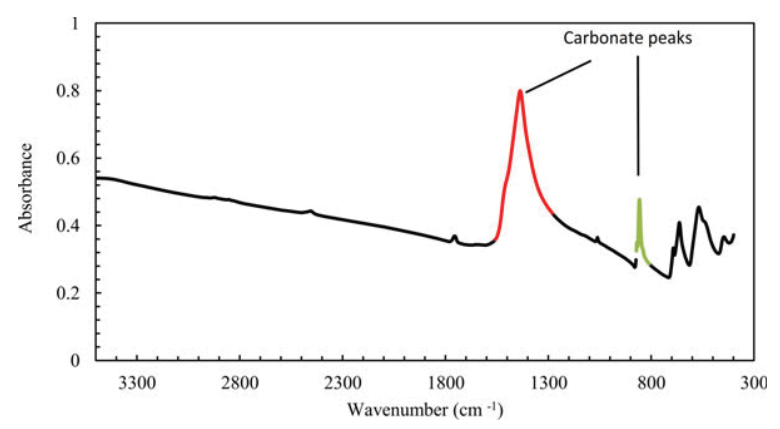

Fig. 8. FTIR spectra of feedstock 1 after thermal treatment at $550^{\circ} \mathrm{C}$ in air.

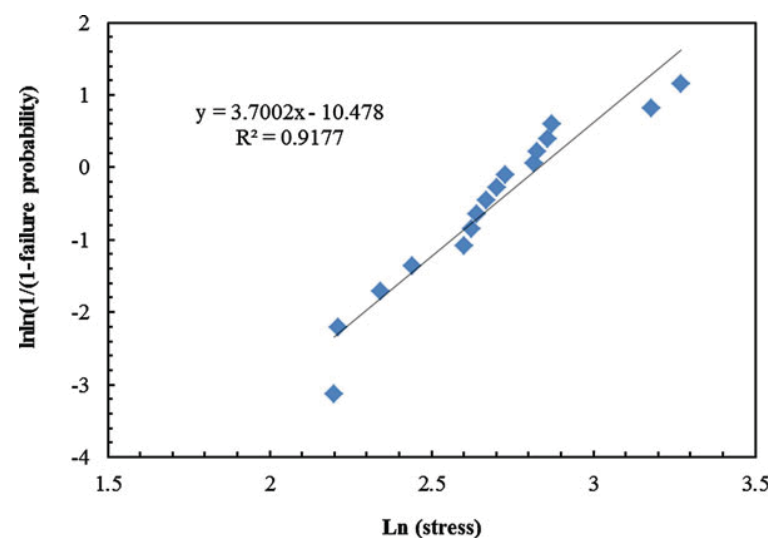

Fig. 9. Weibull plot for sintered tubes made of feedstock 1 .
Table III. Gastightness Test of the Dead-End Tubes at Different Pressures

\begin{tabular}{|c|c|c|c|c|}
\hline Pressure (bar) & Tube 1 & Tube 2 & Tube 3 & Tube 4 \\
\hline 2 & レ & $\nu$ & レ & $\nu$ \\
\hline 4 & レ & $\nu$ & レ & $\nu$ \\
\hline 6 & V & $\nu$ & V & $\nu$ \\
\hline 8 & 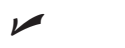 & $\nu$ & レ & $\nu$ \\
\hline 10 & レ & $x$ & レ & $\nu$ \\
\hline 12 & レ & $x$ & レ & $\nu$ \\
\hline 14 & レ & $x$ & レ & $\nu$ \\
\hline 16 & $\nu$ & $x$ & $\nu$ & $\nu$ \\
\hline 18 & レ & $x$ & $\swarrow$ & $\nu$ \\
\hline 20 & レ & $x$ & $\nu$ & $\nu$ \\
\hline 22 & レ & $x$ & $x$ & $\nu$ \\
\hline 24 & & $x$ & $x$ & $\nu$ \\
\hline 26 & レ & $x$ & $x$ & $\nu$ \\
\hline 28 & & $x$ & $x$ & $\nu$ \\
\hline 30 & $\nu$ & $x$ & $x$ & $\nu$ \\
\hline 32 & レ & $x$ & $x$ & $\nu$ \\
\hline 34 & & $x$ & $x$ & $\nu$ \\
\hline 35 & レ & $x$ & $x$ & $\nu$ \\
\hline
\end{tabular}

$\boldsymbol{x}=$ failed; $\boldsymbol{V}=$ gas tight.

The Weibull modulus $(m)$ determined from the mechanical tests is 3.1 and the characteristic strength $\left(\sigma_{0}\right) 15 \mathrm{MPa}$ (Fig. 9). Both values are obvious smaller compared to literature data for BSCF tubular membranes fabricated by isostatic pressing $(m=6.7$ and $\left.\sigma_{0}=130 \mathrm{MPa}\right) .{ }^{17}$ But it has to be considered that the test methods and the loaded volumes are not directly comparable. The details of determining compressive strength and Weibull plot are described elsewhere. ${ }^{18,19}$

All the tubes were gastight up to a pressure of 2 bar. Two of four tubes withstand the maximal applied pressure up to $35 \mathrm{bar}$ (Table III). The remaining two tubes broke at pressures of 10 and 22 bar, but none of them broke at the dead-end part. One broke in the middle of the tubes, and the other at the metal connection.

\section{Conclusion}

Dead-end dense tubular BSCF membranes were successfully prepared using thermoplastic extrusion. Tubes prepared with a binder system based on PE and PW showed axial deformation during extrusion, which could be avoided by using an EVA-based binder system. Samples were completely destroyed during solvent debinding in $n$-hexane. Samples treated in ethanol showed deformation in axial direction during drying. Therefore, a wick- 
ing process was applied to extract PW and SA. TGA showed that about $70 \%$ of PW and SA are removed during the wicking step. The remaining binder was removed by a subsequent thermal annealing up to $600^{\circ} \mathrm{C}$. Nondeformed dead-end tubular membranes with wall thickness of $0.5 \mathrm{~mm}$ were obtained with EVA binder system after sintering. The gastightness test confirmed that the membranes were leak-tight to nitrogen up to the pressure of 35 bar.

\section{Acknowledgments}

The authors would like to acknowledge the financial contribution provided by Swiss Electric Research and the Competence Center for Energy \& Mobility (CCEM) in Switzerland.

\section{References}

1. Z. Chen, R. Ran, Z. Shao, H. Yu, J. C. D. D. Costa, and S. Liu, Ceram. Int., 35 [6] 2455-2461 (2009).
2. M. D. Mat, X. Liu, Z. Zhu, and B. Zhu, Int. J. Hydrogen Energy, 32 [7] 796-801 (2007).

3. Z. Shao, G. Xiong, H. Dong, W. Yang, and L. Lin, Sep. Purif. Technol., 25 [1-3] 97-116 (2001).

4. S. Svarcová, K. Wiik, J. Tolchard, H. J. M. Bouwmeester, and T. Grande, Solid State Ionics, 178 [35-36] 1787-1791 (2008).

5. J. P. Kim, J. H. Park, E. Magnone, and Y. Lee, Mater. Lett., 65 [14] 2168-2170 (2011)

6. Q. Jiang, S. Faraji, D. A. Slade, and S. M. Stagg-Williams, Membr. Sci. Technol., 14 235-273 (2011).

7. F. Liang, H. Jiang, H. Luo, R. Kriegel, and J. Caro, Catal. Today, 193 [1] 95-100 (2012).

8. F. Liang, H. Jiang, T. Schiestel, and J. R. Caro, Ind. Eng. Chem. Res., 49 [19] 9377-9384 (2010)

9. Y. Wei, J. Tang, L. Zhou, Z. Li, and H. Wang, Chem. Eng. J., 183 473-482 (2012).

10. K. Li, Ceramic Membranes for Separation and Reaction. John Wiley, Chichester, U.K. and Hoboken, NJ, 2007.

11. M. Salehi, et al., J. Membr. Sci., 443 237-245 (2013).

12. J. Heiber, F. Clemens, T. Graule, and D. Hülsenberg, Adv. Eng. Mater., 7 [5] 404-408 (2005).

13. M. Salehi, et al., J. Membr. Sci., 382 [1-2] 186-193 (2011).

14. D.-S. Tsai and W.-W. Chen, Ceram. Int., 21 [4] 257-264 (1995).

15. M. T. Zaky, F. S. Soliman, and A. S. Farag, J. Mater. Process. Technol., 209 [18-19] 5981-5989 (2009).

16. M. T. Zaky, J. Mater. Sci., 39 [10] 3397-3402 (2004).

17. E. M. Pfaff, A. Kaletsch, and C. Broeckmann, Chem. Eng. Technol., 35 [3] 455-463 (2012)

18. J. M. Villora, P. Callejas, M. F. Barba, and C. Baudin, J. Eur. Ceram. Soc., 24 [3] 589-594 (2004).

19. W. Weibull, A Statistical Representation of Fatigue Failures in Solids by W. Weibull, Henrik Lindståhl, Stockholm, Sweden, 1949. 